\title{
Relation between nurse educators' empowerment and nursing students' clinical competence
}

\author{
Salmein Ahmed Fath-Elbab1; Safaa Mohammed Abd el-rahman2; Mona Thabet Abd el-baset3
}

1- Bachelor of Nursing, Faculty of Nursing, Minia University,

2- Professor of Nursing Administration, Faculty of Nursing ,Minia University.

3- Lecturer of Nursing Administration Department, Faculty of Nursing, Elminia University.

\begin{abstract}
Background: nurse educators are responsible for the preparation of nursing students for their future profession; they are vital and serve as a critical driving force to lead the progression of the next generation of professional nurses. If nurse educators perceive themselves as empowered in their jobs, they will be more confident in their skills and knowledge, be more engaged in their role. Aim: the aim of this study was to determine relation between nurse educators' empowerment and nursing students' clinical competence. Design: Descriptive correlational research design was used to achieve the aim of the current study. Setting: two nursing technical institute, one affiliated to university and another one affiliated to ministry of health at Minia city. Subjects: The subject of study was include all nurse educators at Minia Nursing technical institutes $(n=20)$ and $50 \%$ of nursing students enrolled at $2{ }^{\text {nd }}$ academic year 2018-2019 ( $n=350)$. Tools: three tools were used to collect data pertinent to the study as: Structural Empowerment Questionnaire; Psychological Empowerment Questionnaire; and Clinical Competence checklist. Results: The study revealed that highest percentage of nursing educators had moderate level of structural empowerment and high level of psychological empowerment. Regarding the total clinical competence mean score, there was highly statistical significance difference $(\mathrm{P}=0.000)$ between nursing students at two institutes in favor to Health Technical Institute had higher mean score $(\mathbf{8 2 . 7} \pm \mathbf{4 . 6})$. Conclusion: this study concluded that, there was a positive correlation between nurse educators' empowerment and nursing students' clinical competence. Recommendations: Periodic training courses should be provided in order to keep nursing students updating knowledge, skills, and attitudes regarding to clinical practice and conducting workshops to develop nurse educators' empowerment.
\end{abstract}

Keywords: nurse educator, empowerment, clinical competence, nurse student.

\section{Introduction}

The demographic changes of the population increased technological advancement, as well as the increased prevalence of chronic illness and disabilities have resulted in the need for changing the health care delivery systems ${ }^{(1,2)}$. This dynamic and uncertain nature of health care environment requires competent professional nurse to manage the rapidly changing environment ${ }^{(1)}$.

Therefore, nurse educators play a vital role in ensuring that the new generation of nurses is prepared to meet the growing demand of health care services. Nurse educators are also instrumental in shaping the future of the nursing profession ${ }^{(3)}$.They represent the spirits of the education process ${ }^{(4)}$. So, many nurse educators have a dream to make a difference in the nursing profession, but this dream is challenging and faces many problems. One of these challenges is lack of nursing empowerment that nurses are still experiencing ${ }^{(5)}$.

Empowerment is the process of increasing the capacity of individuals or group to make choices and to transform those choices into desired action and outcomes ${ }^{(6)}$. It is considered a motivational process of enhancing feeling of self-efficacy among organizational members through the identification of conditions that foster powerlessness ${ }^{(7)}$.

Moreover, the need to produce a competent, confident, critical thinker with the ability to lead, to question, and to be questioned is the core of modern preregistration in nursing educational programs .Despite the qualified professionals' need, nowadays clinical competence of nurses in hospitals and other clinical environments are the concern and the center of attention for managers and the healthcare systems ${ }^{(8)}$.

Thus, competence is a crucial attribute for assuring high-quality, ethical and safe nursing care ${ }^{(9,10)}$. Nurse students' clinical experience in nursing institutes has a longterm effect on their future competence ${ }^{(11)}$. They are required to master multiple task related skills during their education ${ }^{(12)}$, to accurate determine patients' states and predict and cope with the problems that may occur during nursing care ${ }^{(13,14) \text {. }}$

Currently, lack of nurses' clinical competence is one of the most important issues in the provision of quality nursing care ${ }^{(15,16)}$. The expectation of nursing education is to produce graduates who will be competent practitioners upon graduation ${ }^{(17)}$. Therefore, nursing technical institutes are one of the organizations responsible to train nurses who have high level of clinical competence to satisfy the needs of all concerned bodies. For the preparation of these incompetent graduated nurses, literature revealed the contributions of different factors such role of the nurse educators as enabling the integration of theory and practice ${ }^{(18)}$.

In addition, the empowered nurse educator possesses the tools and resources that required developing instructional strategies; so students can attain successful mastery of the designated learning outcomes for the clinical course. With access to opportunity, resources, support, and information; nurse educators possesses the ability to engage in purposeful teaching and enabling the student to integrate theoretical concepts into successful practice ${ }^{(19)}$.

\section{Significance of the study}

Nurse educators have played a critical role in the professional development of nurses, and maintaining and advancing nursing practice standards. They are responsible for advancing practice development and student support ${ }^{(20)}$. Also, in the healthcare systems, nurse educators have the role for helping nursing students to become the type of practitioners who will positively impact patient care and satisfaction ${ }^{(21)}$.

Aliakbari, and Amoli, $2016^{(22)}$ found in their study that teacher empowerment important factor that enhance and improve student performance. Nurse educators who are empowered to make decisions are likely to have the ability to improve student achievement, as improving working 
condition will surely increase teaching quality which leads to positive effects on nursing student performance, learning, and academic performance.

Therefore, an effective role of nurse educators is the most important part in nursing education, because they considered as the change agent in the nursing education, in which, their role help nurse student to gain knowledge, skills, and attitudes, to enhance patient care. There are many researches that identify nurse educator empowerment as an important component to educator. But still now, there is no research that identifies a direct relation between nurse educators' empowerment and student clinical competence. Thus it is important to evaluate the relation between nurse educator empowerment and student clinical competencies

\section{Aim of the study}

The aim of the current study is to determine relation between nurse educators' empowerment and nursing students' clinical competence.

\section{Research questions}

- What are the nurse educators' levels of empowerment at Minia Nursing technical institutes?

- What is the nursing students' clinical competence at Minia Nursing technical institutes?

- What is relation between nurse educators' empowerment and nursing students' clinical competence at Minia Nursing technical institutes?

\section{Subjects and methods \\ Research design:}

Descriptive correlational research design was used to achieve the aim of the current study.

\section{Setting:}

The study was conducted at Minia two nursing technical institute, one affiliated to university and another one affiliated to ministry of health.

\section{Subjects:}

The subject of study was include all nurse educators at Minia Nursing technical institute $(n=15)$ and $50 \%$ of nursing students enrolled at 2nd academic year, 2018-2019 $(n=165)$. And all nurse educators at Health Technical Institute $(\mathrm{n}=5)$ and $50 \%$ of nursing students enrolled at 2 nd academic year, 2018-2019 $(n=185)$. Total number of educators was $(20)$ and total number of students was (350).

\section{Data Collection Tools: \\ Data was collected by using three tools as follows: Tool (I) - Structural Empowerment Questionnaire it was included two parts:}

Part 1: personal data; it was including information about nurse educators; such as: age, gender, residence, nursing qualification, and years of experience.

Part 2: Condition of Work Effectiveness Questionnaire (CWEQ) This tool was developed by Laschinger, et al., (2001) ${ }^{(23)}$ to assess nurse educators' structural empowerment. This tool was adopted and modified by the researcher to be compatible with the nursing institute environment. CEWQ included 19 item divided into 6 subscales components as follow: opportunity included (3 items), information included (3 items), support included (3 items), resources included (3 items), informal power included
(3 items), and formal power included (4 items). Each Item was measured with five points Likert scale as $(1=$ never, $2=$ seldom, 3 = sometimes, $4=$ often, $5=$ always). Scoring system was ranged from 19 to 95 , and divided as follow:

- Low nurse educator structural empowerment from 19 to 44

- Moderate nurse educator structural empowerment from 45 to 69

- High nurse educator structural empowerment from 70 to 95

This scale was also, had two question measured by five point likert scale as $(1=$ strongly disagree, $2=$ disagree, $3=$ agree, $4=$ neutral, $5=$ strongly agree). These two items score were used to confirm construct validity with six components of structural empowerment

Tool (II) - Psychological Empowerment Questionnaire: This tool was developed by Spreitzer (1995) (24) and was adopted by researcher to assess nurse educators' psychological empowerment. It contained 12 item divided into four subscales as follow: Meaning, Competence, Selfdetermination, and Impact (3 items for each subscale). Each item was measured with five points likert scale as $(1=$ strongly disagree, $2=$ disagree, $3=$ agree, $4=$ neutral, $5=$ strongly agree). Scoring system of this tool was ranged from 12 to 60 and divided as follow:

* Low nurse educator psychological empowerment from 12:28

* Moderate nurse educator psychological empowerment from 29:44

* High nurse educator psychological empowerment from 45:60

Tool (III) - Clinical Competence checklist: it was including three parts:

Part 1: Personal data; which included information about nurse students as age, gender, previous education and residence.

Part 2: this part was included the student score of final clinical exam during the time of data collection. The scoring system for this part was as follows:

$\begin{array}{ll}\text { - Poor }=\text { less than } & \text { - } \begin{array}{l}\text { Fair= } 50 \text { to less } \\ \text { than } 65 \%\end{array} \\ 50 \% & \text { Excellent } 85 \% \text { or } \\ \text { - } & \text { mood }=65 \text { to less }\end{array}$

Part 3:

This tool is developed by the researcher based on literature review ${ }^{(25: 33)}$ to assess nursing student clinical competence. The final clinical competence observational checklist contained (66) items divided into two subscales as follows:

- Subscale (I): Nursing Clinical Behaviors, Values and Attitudes: it included (19 items); each item measured with 3 point as $(0=$ Unsatisfactory, $1=$ Need Improvement, $2=$ Satisfactory, and Not observed $=-$ ). This subscale was divided into 3 dimensions as follows:

○ Communication (6 items)

- Responsibility and commitment (6 items)

- Caring and ethics (7 items)

- Subscale (II): Nursing Clinical skills: it included (47 items); each item measured with 3 point as $(0=$ Not Done, 1= Done Incompletely, 2= Done Completely, and Not Applicable =--). This subscale was divided into 5 dimensions as follows:

○ General skills (14 items) 
○ Measuring vital signs skills (4 items)

- Specific skills (11 items)

- Safety and infection control skills (10 items)

○ Drug administration skills (8 items)

Scoring system of this part was ranged from 0 to 132 and divided as follows:

- $\quad$ Poor $=$ less than $50 \%$

- $\mathrm{Good}=65$ to less than $85 \%$

\section{$*$}

The researcher interviewed with nursing educators through morning during the working days of clinical rotation.

* The tools were handed to the nursing educators and researcher waited with them during their working hours to fill it and it was collected after filling. The time required for filling the tools was thirty minutes approximately.

* For nursing students the researcher went to the hospital with nurse educators who supervised the nursing students to fill the observational checklist by asking the nurse educator to support and supplying general essential information and by observation, students were observed performing patient care duties during their clinical day, being limited interacts with the patients, visitors or other hospital personnel.

* Data was collected from Nursing Technical Institute on Sunday per week during first semester of the academic year 2018-2019, it was lasted for three months, and each day, the researcher observed 15:16 students from 9:00 A.M to 1:00 pm.

* Data was collected from Health Technical Institute on Tuesday per week during first semester of the academic year 2018-2019; it was also lasted for three months, and each day the researcher observed filled17:18 students from 9:00 A.M to 1:00 pm.

\section{Ethical consideration}

A written initial approval was obtained from the research ethics committee of the Faculty of Nursing, Minia University. Approval to conduct the study obtained from the Dean of faculty, as well from the Vice dean for education and students affairs in Faculty of Nursing at Minia University. The participants were informed that their participation in the study was completely voluntary and there will be no harm if they not participate in the study. Informed consent was obtained from participating after explaining the nature and benefits of the study. Each assessment sheet was coded and participants' names were not appearing on the sheets for the purpose of anonymity and confidentiality.

A pilot study was conducted on $10 \%$ of student (35) and $10 \%$ of nurse educators (2) to ascertain the clarity, comprehensiveness and applicability of the tools as well as to estimate the appropriate time required to fill the questionnaire. The necessary modification was done.

According to the observation that was done for the students of the pilot; there were 4 items that all students had not performed and had score for "not applicable" for all of them; thus these 4 items were excluded from the final format of the tool. The final format of the tool contained (66 items). Thus, the tool (III) was modified and results of pilot study were not added to the final results.

\section{Study procedure}

* An official letters were granted from the Faculty Dean, the Director of both technical institute of nursing. This letter was included a brief explanation of the objectives of the study.

\section{Statistical analysis:}

Data entry was done using compatible personal computer. Statistical analysis done by using statistical package of social science (SPSS) version 25 and excel for figures. The content of each tool was analyzed, categorized and then coded. Data were presented using descriptive statistics in the form of frequencies and percentages for qualitative variables, and means and standard deviations for quantitative variables. Statistical significance used at $\mathrm{P}$ value $<0.05$.

And comparison of means was performed using paired-sample t-test. Pearson's chi square test (X2) is used to test for the association (or relationship) between the categories of two independent samples (row and column variables) to reflect a real association between these 2 variables in the population. Correlation is used to test the nature and strength of relation between two quantitative / ordinal variables. 
Minia Scientific Nursing Journal (Print) (ISSN 2537-012X) Vol. (7) No. (1) June 2020

\section{Results:}

Table (1): Percentage distribution of the nursing educators according to their personal data

\begin{tabular}{|c|c|c|c|c|}
\hline \multirow{3}{*}{ Personal data } & \multicolumn{4}{|c|}{ Nursing Educators $(\mathrm{n}=\mathbf{2 0})$} \\
\hline & \multicolumn{2}{|c|}{ Nursing technical institute $(n=15)$} & \multicolumn{2}{|c|}{ Health technical institute $(\mathrm{n}=5)$} \\
\hline & No & $\%$ & No & $\%$ \\
\hline \multicolumn{5}{|l|}{ Age/ years } \\
\hline - $\quad 25-29$ & 4 & 26.7 & $\mathbf{0}$ & 0.0 \\
\hline - $\quad 30-34$ & 6 & 40.0 & 5 & 100 \\
\hline - $\quad 35-39$ & 5 & 33.3 & $\mathbf{0}$ & 0.0 \\
\hline Mean + SD & \multicolumn{2}{|c|}{$32.3+3.9$} & \multicolumn{2}{|c|}{$32.0+0.5$} \\
\hline \multicolumn{5}{|l|}{ Gender } \\
\hline - Male & 1 & 6.7 & $\mathbf{0}$ & 0.0 \\
\hline - $\quad$ Female & 14 & 93.3 & 5 & 100 \\
\hline \multicolumn{5}{|l|}{ Residence } \\
\hline - $\quad$ Rural & 10 & 66.7 & 3 & 60.0 \\
\hline Urban & 5 & 33.3 & 2 & 40.0 \\
\hline \multicolumn{5}{|l|}{ Nursing qualification } \\
\hline Baccalaureate & 12 & 80.0 & 5 & 100.0 \\
\hline - $\quad$ Master & 3 & 20.0 & $\mathbf{0}$ & 0.0 \\
\hline \multicolumn{5}{|l|}{ Years of experience } \\
\hline $\begin{array}{l} \\
\end{array}$ & 12 & 80.0 & 3 & 60.0 \\
\hline $\begin{array}{ll} & 10-15\end{array}$ & 3 & 20.0 & 2 & 40.0 \\
\hline
\end{tabular}

Table (1) showed that, more than one third (40.0\%) of nursing educators at Nursing technical institute and all (100) at Health technical institute aged between 30 - 34 years with mean age $(32.3 \pm 3.9$ and $32.0 \pm 0.5$ respectively). The majority (93.3\%) of nursing educators at Nursing technical institute and all (100) at Health technical institute was female. Regarding the residence; two third $(65.0 \%)$ and $(60 \%)$ of nursing educators live in rural area. the majority $(80.0 \%)$ of nursing educators at Nursing technical institute and all $(100 \%)$ at Health technical institute had baccalaureate degree. Speaking about years of experiences, the majority ( $80 \%)$ of nursing educators at Nursing technical institute and $(60 \%)$ at Health technical institute had $(5<10)$ years of experience.

Table (2): Percentage distribution of the nursing students according to their personal data

\begin{tabular}{|c|c|c|c|c|}
\hline \multirow{3}{*}{ Personal data } & \multicolumn{4}{|c|}{ Nursing students $(\mathrm{n}=\mathbf{3 5 0})$} \\
\hline & \multicolumn{2}{|c|}{ Nursing technical institute $(n=165)$} & \multicolumn{2}{|c|}{ Health technical institute $(n=185)$} \\
\hline & No & $\%$ & No & $\%$ \\
\hline \multicolumn{5}{|l|}{ Age/ years } \\
\hline - $19-20$ & 104 & 63.0 & 185 & 100.0 \\
\hline - $21-22$ & 61 & 37.0 & 0 & 0.0 \\
\hline Mean+ SD & \multicolumn{2}{|c|}{$20.2 \pm 0.970$} & \multicolumn{2}{|c|}{$19.5 \pm 0.2$} \\
\hline \multicolumn{5}{|l|}{ Gender } \\
\hline - Male & 79 & 47.9 & 34 & 18.4 \\
\hline - Female & 86 & 52.1 & 151 & 81.6 \\
\hline \multicolumn{5}{|l|}{ Residence } \\
\hline - $\quad$ Rural & 136 & 82.4 & 164 & 88.6 \\
\hline - Urban & 29 & 17.6 & 21 & 11.4 \\
\hline \multicolumn{5}{|l|}{ Previous Education } \\
\hline - Secondary nursing school & 0 & 0.0 & 185 & 100.0 \\
\hline - High school & 165 & 100.0 & 0 & 0.0 \\
\hline
\end{tabular}

Table (2) presented that, near to two third (63.0\%) of nursing students at Nursing Technical Institute aged between $19-20$ years with mean age $(20.2 \pm 0.970)$; more than half $(52.1 \%)$ of them were female; the majority $(82.4 \%)$ of them live in rural area, and all $(100.0 \%)$ had high school. Regarding to Health Technical Institute, table (2) shows that all (100.0\%) of nursing students aged between $19-20$ years with mean age $(19.5 \pm 0.2)$; the majority $(81.6 \%)$ of them were female; the majority $(88.2 \%)$ of them lived in rural area; and all $(100.0 \%)$ of them had secondary nursing school.

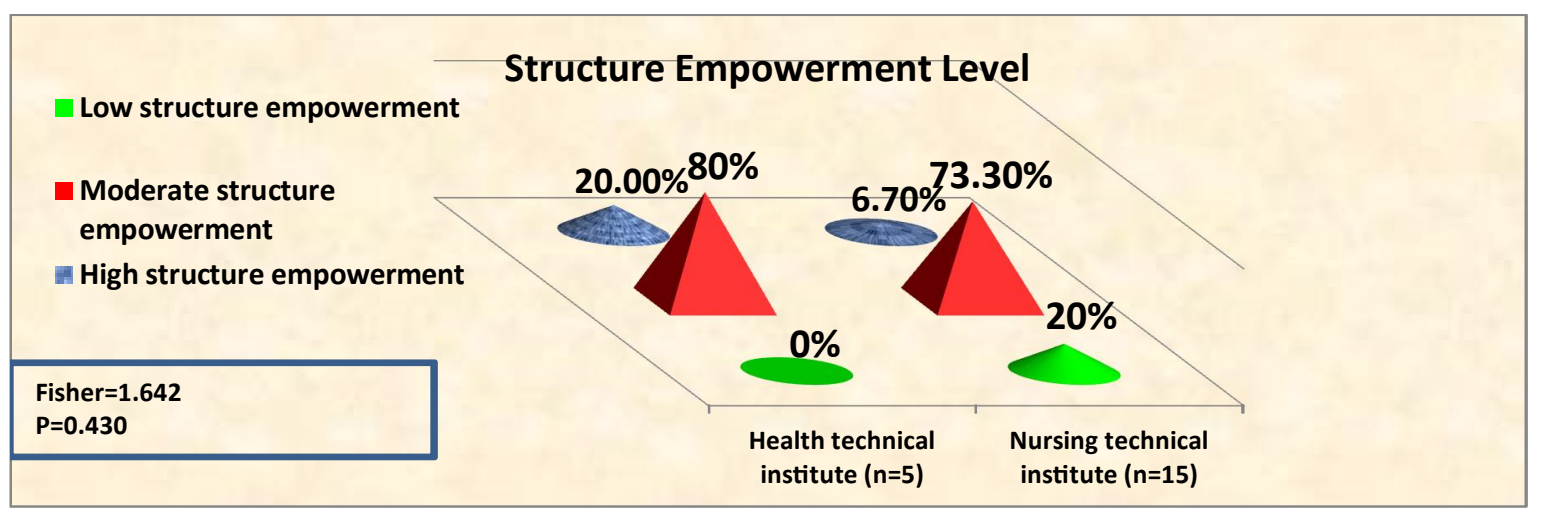

Figure (1): Levels of total structure empowerment among nursing educators $(n=20)$

Figure (1) revealed that nursing educators had highest percentage for moderate level at Health Technical Institute (80\%) and at Nursing Technical Institute (73.30\%); also, there was (20\%) of them at Health Technical Institute and (6.7\%) at Nursing Technical 
Minia Scientific Nursing Journal (Print) (ISSN 2537-012X) Vol. (7) No. (1) June 2020

Institute had high level of structure empowerment; with no statistically significant differences between them at two institutes; with no statistical significance difference.

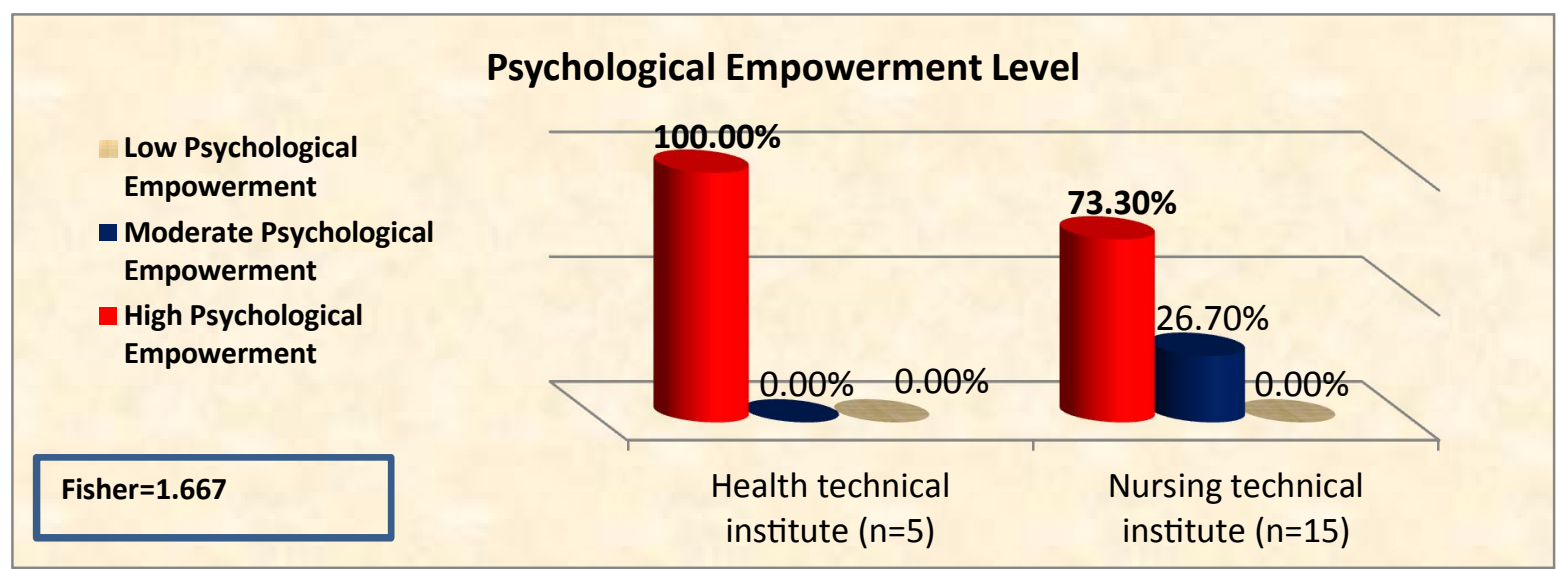

Figure (2): Levels of total Psychological empowerment among nursing educators $(n=20)$

Figure (2) displayed that nursing educators had highest percentage for high level as all (100\%) at Health Technical Institute and neat three quarter (73.3\%) at Nursing Technical Institute; also, no one (0\%) of them at Health Technical Institute and at Nursing Technical Institute had low level of psychological empowerment; with no statistically significant differences between them at two institutes.

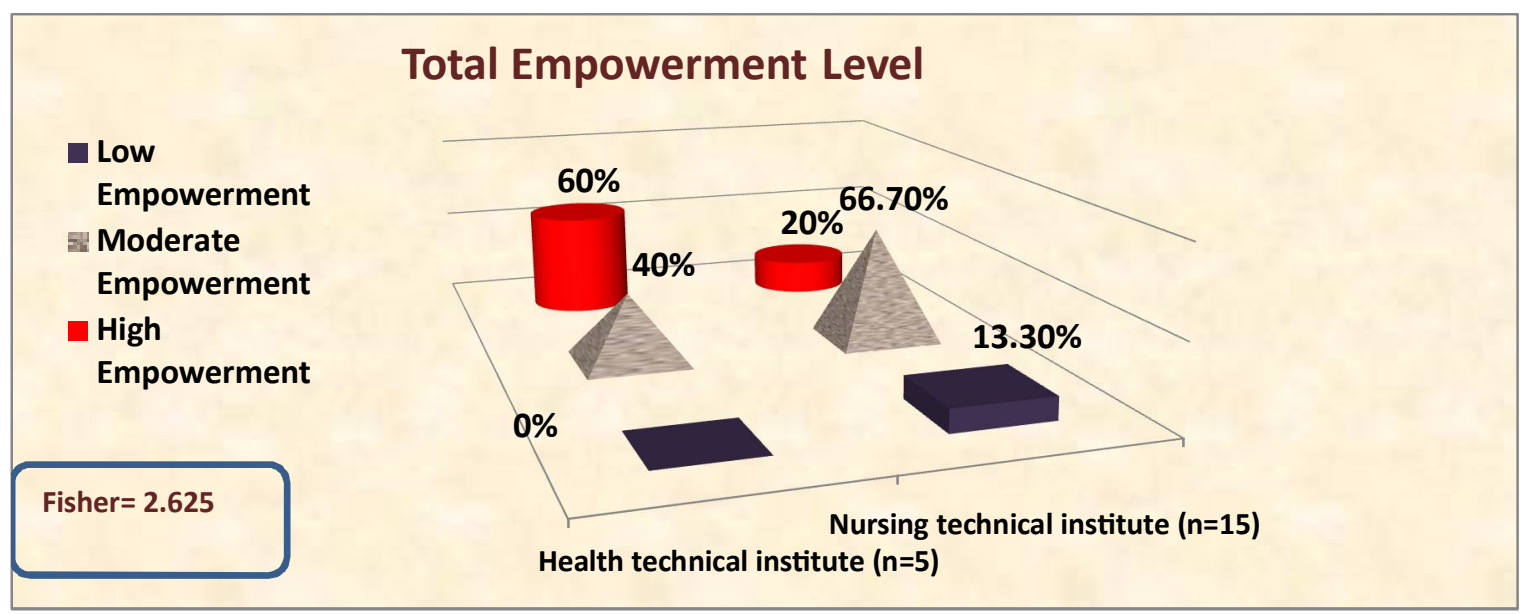

Figure (3): Total level of empowerment among nursing educators $(n=20)$

Figure (3) showed that at Health Technical Institute, there was near to two third $(60 \%)$ of nursing educators had high level and $(40 \%)$ of them had moderate level of total empowerment; while at Nursing Technical Institute, there was two third of nursing educators $(66.7 \%)$ had moderate level and only (20\%) of them had high level of total empowerment; with no statistically significant differences between them at two institutes.

Table (3): Mean scores of nursing students regarding their clinical competence

\begin{tabular}{|c|c|c|c|c|}
\hline \multirow{3}{*}{ Clinical Competence } & \multicolumn{2}{|c|}{ Nursing students $(\mathrm{N}=\mathbf{3 6 0})$} & \multicolumn{2}{|c|}{ Test of significance } \\
\hline & $\begin{array}{l}\text { Nursing technical } \\
\text { institute }(n=165)\end{array}$ & $\begin{array}{l}\text { Health technical } \\
\text { institute }(n=185)\end{array}$ & \multirow{2}{*}{ t- test } & \multirow{2}{*}{$P$ - Value } \\
\hline & Mean \pm SD & Mean +SD & & \\
\hline \multicolumn{5}{|c|}{ Subscale (I): Nursing clinical behaviors, values and attitudes } \\
\hline - Communication (6) & $7.7 \pm 2.3$ & $7.9 \pm 1.9$ & 0.821 & 0.412 \\
\hline - Responsibility and commitment (6) & $10.1 \pm 1.0$ & $9.1 \pm 1.3$ & 7.745 & $0.000 * *$ \\
\hline - Caring and ethics (7) & $10.6 \pm 1.6$ & $10.9 \pm 2.0$ & 1.912 & 0.057 \\
\hline Total of subscale (I) (19 items) & $28.3 \pm 3.4$ & $27.8 \pm 3.9$ & 1.221 & 0.223 \\
\hline \multicolumn{5}{|l|}{ Subscale (II): Nursing clinical skills } \\
\hline - General skills (14) & $14.7 \pm 1.2$ & $14.1 \pm .8$ & 2.457 & $0.015 *$ \\
\hline - Measuring Vital signs (4) & $2.8 \pm 0.7$ & $2.2 \pm 1.06$ & 2.185 & $0.034 *$ \\
\hline - Specific skills (11) & $5.5 \pm 0.9$ & $9.0 \pm 1.5$ & 26.665 & $0.000 * *$ \\
\hline - Safety and infection control (10) & $16.1 \pm 0.8$ & $16.1 \pm 0.8$ & 0.175 & 0.861 \\
\hline - Medication administration (8) & $8.0 \pm 1.3$ & $8.8 \pm 1.4$ & 5.798 & $0.000 * *$ \\
\hline Total of subscale (II) (47 items) & $46.5 \pm 2.0$ & $50.4 \pm 2.4$ & 16.212 & $0.000 * *$ \\
\hline Total of clinical competence (66 items) & $77.3 \pm 4.1$ & $82.7 \pm 4.6$ & $\mathbf{1 1 . 4 8 6}$ & $0.000 * *$ \\
\hline
\end{tabular}


Table (3) showed that nursing students at Health Technical Institute had higher mean score (7.9 \pm 1.9$)$ for (communication

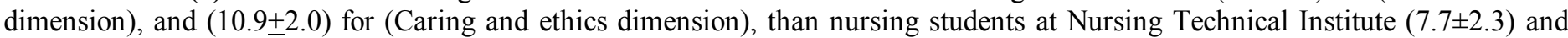
$(10.6 \pm 1.6)$ respectively with no statistically significance difference $(\mathrm{P}=0.412)$ and $(\mathrm{P}=0.057)$ respectively. While, nursing students at Nursing Technical Institute (10.1 \pm 1.0$)$ had higher mean score than nursing students at Health Technical Institute (9.1 \pm 1.3$)$ for (responsibility and commitment dimension) with highly statistical significance difference $(\mathrm{P}=0.000)$.

The nursing student at Nursing Technical Institute had highest mean score for "General skills" and "Measuring Vital signs" (14.7 \pm 1.2 and $2.8 \pm 0.7$ respectively) than nursing student at Health Technical Institute; with statistical significance difference $(\mathrm{P}=0.015$, and 0.034 respectively). While nursing student at Health Technical Institute had highest mean score for specific skills and Medication administration" ( $9.0 \pm 1.5$ and $8.8 \pm 1.4$ respectively) than nursing student at Nursing Technical Institute; with highly statistical significance difference $(\mathrm{P}=0.000)$. No statistical significance differences founded between students for the safety and infection control dimension $(\mathrm{p}=0.861)$.

Regarding total mean score of subscale (I), there was no statistical significance difference between nursing students at two institutes $(\mathrm{P}=0.223)$. While; there was highly statistical significance difference between nursing students at two institutes $(\mathrm{P}=0.000)$ regarding the total mean score of subscale (II). Speaking about total clinical competence mean score, there was highly statistical significance difference $(\mathrm{P}=0.000)$ between nursing students at two institutes in favor to Health Technical Institute had higher mean score $(82.7 \pm 4.6)$.

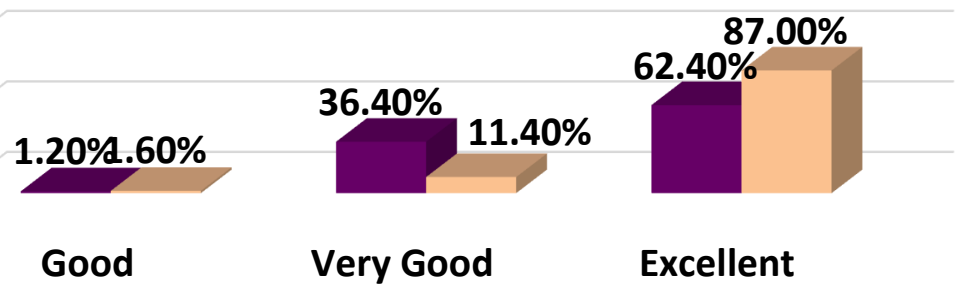

Nursing Technical Institute $\quad$ Health Technical Institute

Figure (4): Nursing students' final clinical exam scores according to their clinical institutes $(n=350)$

Figure (4) illustrated that near to two third (62.4\%) of nursing student at Nursing Technical Institute VS the majority (87.0) of nursing student at Health Technical Institute had excellent levels regarding their clinical area score. While more than one third $(36.4 \%)$ of them VS (11.4\%) had very good levels respectively.

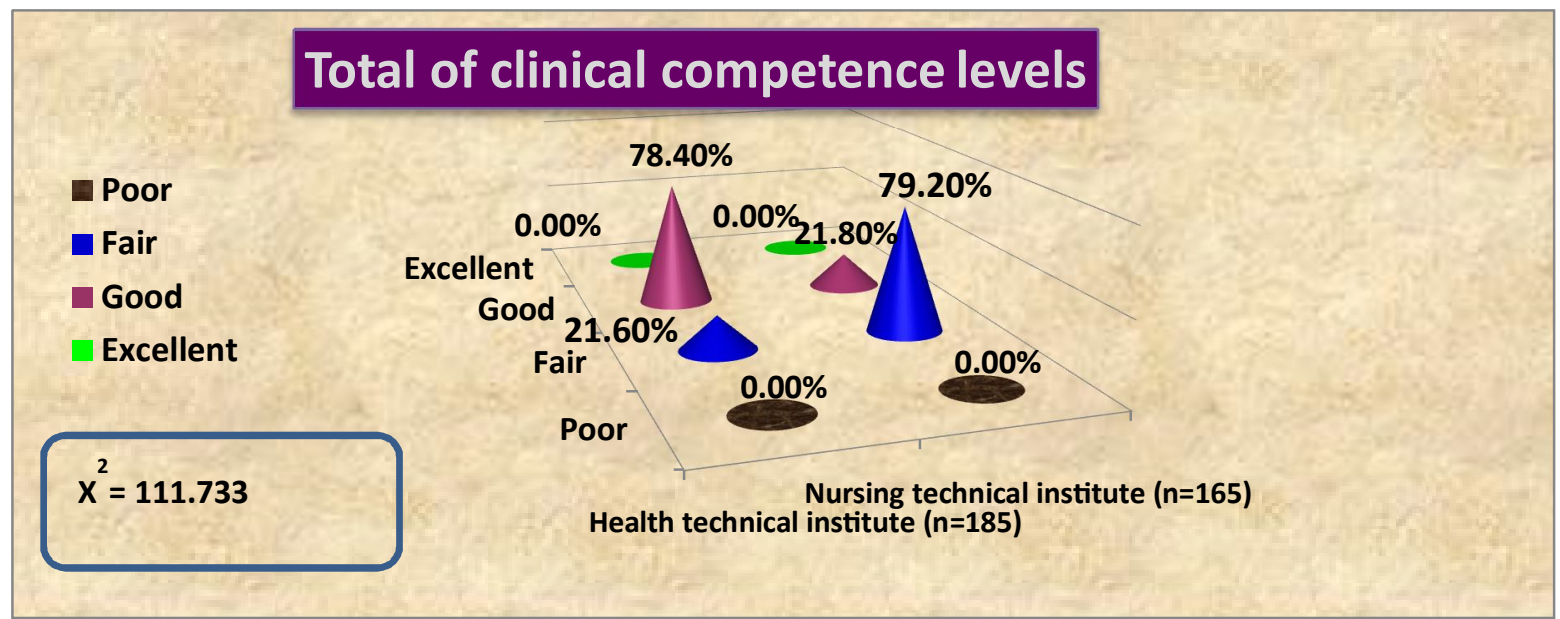

Figure (5) Nursing students' levels regarding their total score levels of clinical competence $(\mathbf{n}=\mathbf{3 5 0})$

Figure (5) displayed that, majority of nursing students (79.2\%) at Nursing Technical Institute had fair level; while majority of nursing students (78.4\%) at Health Technical Institute had good level regarding their total clinical competence; as well as no one $(0 \%)$ had excellent level; with highly statistical significance differences between nursing students at two institutes $(\mathrm{P}=0.0001)$.

Table (4): Correlation between nursing students' clinical competence and their clinical score and nursing educators' empowerment

\begin{tabular}{|c|c|c|c|c|}
\hline \multirow{4}{*}{ Variables } & \multicolumn{4}{|c|}{ Nursing students $(\mathrm{n}=\mathbf{3 5 0})$} \\
\hline & \multicolumn{2}{|c|}{$\begin{array}{l}\text { Nursing technical institute } \\
(\mathrm{n}=165)\end{array}$} & \multicolumn{2}{|c|}{ Health technical institute $(n=185)$} \\
\hline & \multicolumn{4}{|c|}{ Total score of clinical competence } \\
\hline & $\mathbf{r}$ & p-value & $\mathbf{r}$ & $p$-value \\
\hline Final Clinical Exam Score & 0.157 & $0.04 *$ & 0.187 & $0.02 *$ \\
\hline Nurse Educators' Empowerment & 0.542 & $0.01 *$ & 0.431 & $0.05 *$ \\
\hline
\end{tabular}

Table (4) presented that there were positive weak significant correlation between nursing student clinical competence and their final clinical exam score at Nursing Technical Institute which $(\mathrm{r}=0.157$ and $P$ - value 0.04$)$ and at health technical institute which ( $\mathrm{r}=0.187$ and $P$ - value 0.02 ). Also, there were positive moderate significant correlation between nursing student clinical 
competence and nurses educator empowerment at Nursing Technical Institute which $(\mathrm{r}=0.542$ and $P-$ value 0.01$)$ and at Health Technical Institute which $(\mathrm{r}=0.431$ and $P$ - value 0.05$)$

\section{Discussion:}

Nursing is both an art and science ${ }^{(34)}$. The science of nursing involves a body of abstract knowledge and the art of nursing involves the creative use of this knowledge to serve people ${ }^{(35)}$. When educating nursing students, a balance is needed between the knowledge obtained in the theory class and application of that theory in the clinical setting ${ }^{(36)}$.

Nurse educators are vital and serve as a critical driving force to lead the progression of the next generation of professional nurses and meet the rapidly changing landscape of nursing practice and education ${ }^{(37)}$. The future of nursing education and the education of the next generation of professional nurses must be empowered through the expertise of qualified nurse educators and administrators in nursing $\operatorname{programs}^{(38)}$.

Regarding the personal data of nurses educators it was noted that, more than one third of nursing educators at Nursing technical institute and all at Health technical institute aged between 30- 34 years . The majority of nursing educators at Nursing technical institute and all at Health technical institute was female. Regarding the residence; two third $(65.0 \%)$ and $(60 \%)$ of nursing educators live in rural area. the majority of nursing educators at Nursing technical institute and all at Health technical institute had baccalaureate degree. Speaking about years of experiences, the majority of nursing educators at Nursing technical institute and at Health technical institute had $(5<10)$ years of experience..

Regarding the personal data of students it was noted that near to two third of nursing students at Nursing technical institute aged between 19- 20 years, more than half of them were female, majority of them lived in rural area, and all had high school. Regarding to Health technical institute, all of nursing students aged between 19- 20 years, majority of them were female, majority of them lived in rural area, and all of them had secondary nursing school.

The result of the current study revealed that highest percentage of nurse educators at two institutes had moderately structural empowerment. These findings may be due to the highest percent of the study subject were adult nurse educators (less than 40 years), so they accept the work challenges, need to refine their knowledge and skills, and searching for opportunities to improve their position in the work.

This result was the line with Sarmiento et al. (2004) (39) who reported that College educators perceived themselves to be only moderately empowered; this is likely to be related to the nature of their roles. Educators are expected to attend professional conferences to remain up-to-date. These conferences provide them with opportunities to develop new knowledge and also to network with others within and outside the organization who might be able to provide support.

Also, this result of the present study was consistent with Dunker (2014) ${ }^{(40)}$ who reported that nursing faculty members, perceived themselves to be moderately structurally empowered. Also El-Dahshan and Dorgham (2013) ${ }^{(41)}$ reported that nurses experienced moderate level of structural empowerment. Also El-Demerdash and Obied (2016) ${ }^{(42)}$ results showed that around half of the study subject had a moderate and low level of structural empowerment. Also, Valdez, Cayaban and Mathews (2019) ${ }^{(43)}$ reported that majority of the respondents have a moderate level of structural empowerment.
This finding was not consistent with Taha (2012) ${ }^{(44)}$, who found that nurses at El-Manial University Hospital had low access to workplace empowerment structure, as well as, Abdelhamied (2017) ${ }^{(45)}$ reported that nurse staff had low level of structural empowerment. Also, Hassona (2013) ${ }^{(46)}$ reported that more than half of the nursing staffs (59\%) were not empowered at their work. Also Gabra (2019) ${ }^{(47)}$ showed that the level of empowerment among studied nurses Near to two third of studied nurses have low empowerment level. While more than one third of them have moderate empowerment, and the minority of them have high empowerment level. The study findings revealed that less than half of the staff nurses in the study sample had empowerment in their work environment.

Concerning levels of psychological empowerment among nurse educators highest percentage of nurse educators had high level of psychological. This might due to the nurse educators had moderate structural empowerment which had direct effect on psychological empowerment, and felt that they had an influence on their daily work, were independent, had autonomy with regard to the manner in which they performed their jobs and were proud of their jobs.

This result of the present study was consistent with, Nasiripour and Siadati (2011) ${ }^{(48)}$ who indicated that the majority of nurses in their hospitals were perceived psychological empowerment positively. Also, Rawat (2011) (49) reported that working professional employee perceived themselves to be empowered. Also, Ibrahim, El-Magd and Sayed (2014) ${ }^{(50)}$ study indicated that the majority of nurses were perceived psychological empowerment as moderate level.

Also, Saif and Saleh (2013) ${ }^{(51)}$ reported that the employees perceived themselves as highly psychologically empowered, El-Demerdash and Obied (2016) ${ }^{(42)}$ reported that $(77.4 \%)$ of the study subjects had a high level of psychological empowerment. Royan et al., (2017) ${ }^{(52)}$ reported that Nurses' psychological empowerment was in a moderate level. Also, the result of the present study was inconsistent with Abdelhamied (2017) ${ }^{(\mathbf{4 5})}$ who reported that nurses' staff had low psychological empowerment.

Regarding total scores of empowerment (structural and psychological), it was noted from the current study that the highest percentage of nurse educators at Health Technical Institute had high level of total empowerment; while the highest percentage of nurse educators at Nursing Technical Institute had moderate level empowerment scores. This result may be due to the nursing educators at Health Technical Institute had high mean score for structural and psychological empowerment

This result was in the same line with El-Demerdash and Obied (2016) ${ }^{(42)}$ who reported that study subjects of nurses were empowered structurally and psychologically. Also, Valdez, Cayaban and Mathews (2019) ${ }^{(43)}$ showed that the nursing faculty members from Oman reported moderate levels of empowerment. This result was inconsistent with Abdelhamied (2017) ${ }^{(45)}$ that reported that nurses' staff had low level of empowerment. Also, El-Dahshan and Dorgham (2013) ${ }^{(41)}$ who reported that the most of nurses worked in Shebin Elcom hospital had low empowerment

The present study showed that nursing students at Health Technical Institute had higher mean score for 
(communication dimension), and for (Caring and ethics dimension), than nursing students at Nursing Technical Institute. This may due to nursing students at Health Technical Institute had previous contact with patients in the last years of nursing school that give them such experience in how to deal with patients, nurse staff and physician using good verbal and non-verbal communication and using good attitudes toward patient.

The result of the present study is consistent with Tork et al., (2018) ${ }^{(53)}$ that reported most of nursing students in the Qassim region had trained in hospitals for three semesters or more which subsequently exhibit an understanding of communication. Also, this result is consistent with Bijani (2017) ${ }^{(\mathbf{4 5})}$ study that showed that the nursing students adhered to these ethical codes more than the working nurses and the highest average scores for adherence to ethical codes among nursing students pertained to "respecting the client/patients' privacy when performing nursing interventions". Also, Radwan (2018) ${ }^{(55)}$ reported that more than half of nursing graduates reported that their level of competence as good in ethics and values during nursing care.

On the other hand, it was inconsistent with Xie et al., (2016) ${ }^{(56)}$ who revealed that nursing students at the beginning of practice sessions showed that majority of nursing students had poor skills in clinical, treatment, and interpersonal communication and they need extra training. Also it is not consistent with Shafakhah et al., (2015) (57) who demonstrated that most nursing students required improvement in their communication skills in both clinical communication behavior and treatment communication ability.

Also, the current study showed that nursing students at Nursing Technical Institute had higher mean score than nursing students at Health Technical Institute for responsibility and commitment dimension. This may due to feeling fear of clinical instructor evaluation and fearing from repeat or fail. On the other hand nursing students at health technical feeling bored of daily routine in the clinical rotation as they since five years in the clinical area, this lead to less responsibility and commitment. This result is inconsistent with Awuah-Peasah, Sarfo and Asamoah, (2013) ${ }^{(58)}$ who showed that $(41 \%)$ of the respondents stated that the nursing students did not show commitment to clinical work.

The study showed that the nursing student at Nursing Technical Institute had highest mean score for "general skills" and "measuring vital signs" than nursing student at Health Technical Institute; While nursing student at Health Technical Institute had highest mean score for "specific skills" and "medication administration" than nursing student at Nursing Technical Institute. This may be due to the difference in the system of distribution of students in clinical area; for example in the Health Hospitals where the nursing students at Health Technical Institute had their training; there is a shortage in nursing staff and the students used to cover this regardless their clinical rotation, instead of meeting the clinical training outcomes; consequently, the student does not commit to one patient and perform the required and essential tasks for the patients as medication administration and some specific skills. on the other hand students at Technical Nursing Institute were trained in university hospitals where there is a sufficient number of nursing staff and obligated to one patient and makes a comprehensive assessment for him; this allow to measure vital signs in competent manner .
This result is consistent with Radwan (2018) ${ }^{(55)}$ who reported that more than half nursing graduates reported that their level of competence was good in subscales of general nursing care and technical care. Also, Kajander-Unkuri (2014) $^{(59)}$ reported that medication administration was selfassessed by nursing students as very good level of competence and students' self-assessed their nursing skills related to patients' vital signs on either good or very good level.

In this study, two methods were applied to assess the clinical competence of nursing students; researcher observation and nurse educators' clinical exam. As for the researcher observation; the current study revealed that majority of nursing students at Nursing Technical Institute had fair level; while majority of nursing students at Health Technical Institute had good level regarding their total clinical competence; as well as no one had excellent level. This may due to nursing students at health technical institute have more experience and knowledge than nursing students at technical nursing institute because they studied nursing sciences for three years in nursing school, and they did a lot of practical training, which led to making their level better.

This is agreed by Lawal et al., (2015) ${ }^{(60)}$ who stated that clinical experience is to allow nursing students to learn how to apply principles and theories learnt in class in the clinical setting. Also, this is consistent with Benner's (1984) (61) who stated that there was a theoretically systematic correlation between the length of experience and competence. The reason for these differences is likely due to the amount of time the students devoted to practicing their clinical skills.

As regarding to the second methods of assessment clinical competence of students the clinical score at clinical exam, the current study showed that near to two third of nursing student at Nursing Technical Institute VS the majority of nursing student at Health Technical Institute had excellent levels regarding their clinical area score. While more than one third of them VS (11.4\%) had very good levels respectively

This may be due to that there was briefing conducted by teachers for nursing students before their skill laboratory examination. As a result, students know well enough concerning the requirement of their skill examination and perhaps the students realized the importance of being able to safely execute these procedures; so, students practiced more often in their skill labs. Also, the examination take place inside the laboratory where there are no patients but rather on dolls, which reduces the stress or anxiety of the student from making mistakes that harm the patients or dealing with him; in addition to the students being evaluated on specific steps according to practical part only and thus their behaviors, values, and attitudes doesn't been assessed.

This is consistent with Joseph -Dlama and Umar (2015) ${ }^{(62)}$ reported that high levels of stress and anxiety was the highest ranking by respondents as inhibiting clinical performance. Also, Gemuhay et al., (2019) ${ }^{\mathbf{( 6 3 )}}$ who reported in his study that anxiety among the nursing student was related to fear of making mistakes is a factor leading to lack of competency and affect negatively clinical practice.

To conclude, a significant correlation was found between empowerment and clinical competency (skill examination in the laboratory evaluation and direct observation evaluation). Therefore, it could be predicted that increasing empowerment leads to clinical competency development. No study was founded to investigate the relation between educators' empowerment and students' clinical competency, but studies such as Aliakbari, and Amoli, 2016 
(22) entitled the teacher empowerment important factor that enhance and improve student performance. Also, Fikre (2016) ${ }^{(64)}$ (entitled "Effect of spiritual intelligence on mental health") and /have shown the effect of teacher empowerment on student achievement and performance. So, it could be concluded that educators' empowerment could be effective on performance and, consequently, on level of competence of students.

\section{Conclusion:}

It can be concluded from the current study that nurse educators' empowerment has a buffering effect on student's clinical competence level. Nurse educators' empowerment is a main factor that contributes to moderate competence level among second year nursing students studying in technical institutes in Minia. Moreover, from this study it can be concluded that second year nursing students had moderate level of clinical competence. And, there was a positive statistical significant relation between nurse educators' empowerment and nursing students' clinical competence.

\section{Recommendation}

1. Periodic refresher training courses should be provided in order to keep nursing students of updating knowledge, skills, and attitudes regarding to clinical practice.

2. Conducting workshops to develop nurse educators' empowerment.

3. Qualifying exams should be done for students before their practicing in clinical setting.

4. Educational programs regarding clinical competence should be organized for students at the time of commencement of their training and before their graduation.

\section{References}

1. Bifftu B, Dachew B, Tiruneh B, Kelkay M, Bayu N. Perceived clinical competence among undergraduate nursing students in the University of Gondar and Bahir Dar University, Northwest Ethiopia: A Cross-Sectional Institution Based Study. J Adv Nurs. 2016; 2016: 1-7.

2. Ahmed NG, Adam SM, AL-Moniem IA. Patient safety: assessing nurses' perception and developing an improvement plan. Life Sci J. 2011; 8(2): 53-64.

3. Daily nurse staff. Nurse educators' vital role in the future of nursing, blog, news, sponsored post. Springer publishing company. Jun 30/2017. Available at http://daily nurse.com/nurse educators vital role future nursing.

4. Naser AN. Designing a performance standard for teachers of five years nursing school [master thesis]. Egypt: Nursing administration department, Faculty of Nursing, Banha University; 2013.

5. Dweik G, Al Daken L, Abu Snieneh H, Ahmad M. WorkRelated Empowerment among Nurses: Literature Review. IJPQM. 2015; 19(2): 168-86.

6. Huessein RH. Factors affecting on work empowerment among nurses at main Assuit university hospital [master thesis]. Egypt: Nursing administration department, Faculty of Nursing, Assuit University; 2012.

7. Atia HM. Motivating wok factors and empowerment among staff nurses at benha university hospital [master thesis]. Egypt: Nursing administration department, Faculty of Nursing, Benha University; 2012.

8. Roberts K, Lockhart R, Sportsman S. A competency transcript to assess and personalize new graduate competency. J Nurs Adm. 2009; 39(1):19-25.
9. Flinkman M, Leino -kilpi H, Numminen O, Jeon Y, Kuokkanen N, Mertoja R. Nurse competence scale: A systematic and psychometric review. J Adv Nurs. 2017; 73(5):1034-50.

10. Kendall-Gallagher D, Blegen MA. Competence and certification of registered nurses and safety of patients in intensive care units. Am J of Crit Care. 2009; 18(2): 106-16.

11. Cheng CY, Liou SR. Perceptions of clinical competence among nurse pre graduates: Do different types of nursing programs make a difference. J Nurs Educ Pract. 2013; 3(9):139-47.

12. Cant R, McKenna L, Cooper S. Assessing preregistration nursing students' clinical competence: A systematic review of objective measures .Int J Nurs Pract. 2013; 19(2):163-76.

13. Nehrir B, Vanaki Z, Mokhtari Nouri J, Khademolhosseini SM, Ebadi A. Competency in nursing students: a systematic review. Int J Travel Med Glob Health. 2016; 4(1):3-11.

14. Khatiban M, Sangestani G. The effects of using problem-based learning in the clinical nursing education on the students' outcomes in Iran: A quasi-experimental study. J Nurs Educ Pract. 2014; 14(6):698-703.

15. Berkow S, Virkstis K, Stewart J, Conway L. Assessing new graduate nurse performance. J Nurs Adm. 2008; 38(11):468-74.

16. Aiken LH, Clarke SP, Cheung RB, Sloane DM, Silber GH. Educational levels of hospital nurses and surgical patient mortality. JAMA. 2003; 290(12): 1617-23.

17. Barakat $G$. clinical instructor's opining about their role versus nursing students' opinion at technical institute of nursing [master thesis]. Egypt: Nursing administration department, faculty of nursing, Cairo University; 2014.

18. Bergjan M, Hertel F. Evaluating students' perception of their clinical placements - testing the clinical learning environment and supervision and nurse teacher scale (CLES+Tscale) in Germany. J Nurs Educ Today.2013; 33(11):1393-8.

19. Murthy L. Factors That Influence Empowerment In Adjunct Faculty Members. [Doctoral Thesis]. United State: Walden University; 2015.

20. Sayers J, Digiacomo M., Davidson, P. The Nurse Educator Role In The Acute Care Setting In Australia: Important But Poorly Described. Aust J Adv Nurs. 2011; 28(4):44-52.

21. Mahmoud HG. Effect of Nurse Educators Teaching Style on Learning of Baccalaureate Nursing Students in Clinical Learning Environment [Master Thesis]. Egypt: Nursing Administration Department, Faculty of Nursing, Mansoura University; 2017.

22. Aliakbari M, Amoli FA. The effects of teacher empowerment on teacher commitment and student achievement. Mediterr J Soc Sci. 2016; 7(4)

23. Laschinger H, Finegan J, Shamian J, Wilk P. Impact of structural and psychological empowerment on job strain in nursing work settings: expanding Kanter's model. The J Nurs Admi. 2001; 31(5):260-72.

24. Spreitzer GM. Psychological empowerment in the workplace: dimensions, measurement, and validation. Acad Manage J. 1995; 38(5):1442-65.

25. Liou R, Cheng CY. Developing and validating the clinical competence questionnaire: a self-assessment instrument for upcoming baccalaureate nursing graduate. J Nurs Educ Pract. 2014; 4(2):56-66.

26. Weis D, Schank M. Development and psychometric evaluation of the nurses' professional values scale. J Nurs Meas. 2009; 17(3):221-31.

27. Goz F, Gecckil E. Nursing students' professional behaviors scale validity and realiability. J med sci. 2010; 26(4): 938-41.

28. Raisanen A. Level of know-how of persons graduating nurses [doctoral thesis]. Turku: university of Turku; 2002.

29. Meretoja R, Isoaho H, Leino-kilipi H. Nurse competence scale: development and psychometric testing. J Adv Nurs. 2004; 47(2): 124-33.

30. Walsh T, Jairath N, Paterson M, Grandjean C. Quality and safety for nurses clinical evaluation tool. J Nurs Educ. 2010; 49(9): 517-22. 
31. Amanda S, Angele D, Rebecca L. Progressive clinical evaluation tools based on the Quality and Safety Education in Nursing competencies. J Nurs Educ Pract. 2014; 4(2): 116-22.

32. Fentianah NA. Impact of nursing competence on quality of nursing care and safety of nursing practice [doctoral thesis]. University of phoenix; 2012.

33. Lavoie P, Michaus C, Belisle M, Boyer L. Learning theories and tools for the assessment of core nursing competencies in simulation: A theoretical review. J Adv Nurs. 2018; 74: 239-50.

34. Bifftu BB, Dachew BA, TirunehBT, Ashenafie TD, Tegegne ET, Worku WZ. Effective clinical teaching behaviors: views of nursing students and nurse educators at University of Gondar, Northwest Ethiopia: cross-sectional institution based study. J Caring Sci. 2018; 7 (3):119-25

35. Zabat Kan E, Stabler-Haas S. Fast/acts/or the clinical nursing instructor: Clinical teaching in a nutshell. 2nd ed. New York: Springer Publishing Company. 2009.

36. Toelke LD. The clinical nurse instructor: best practices in orienting newly hired clinical faculty [master thesis]. Washington State University; College of Nursing; 2012.

37. Aduddell KA, Dorman GE. The Development of The Next Generation Of Nurse Leaders. J Nurs Educ. 2010; 49:168-171.

38. Damask-Bembenek B. Perceptions of Effective Forms of Structural Empowerment Models by Nursing Faculty members And Administrators. North central University; 2015.

39. Sarmiento TP, Laschinger HKS, Iwasiw C. Nurse educators' workplace empowerment, burnout, and job satisfaction: testing Kanter's theory. J Adv Nurs. 2004; 46(2):134-143.

40. Dunker K. Perception of empowerment in full time faculty. Austin Journal of Nursing Healthcare. 2014; 1: 1001.

41. El Dahshan MEA, Dorgham LS. The Effect of Structural and Psychological Empowerment on ccupational Burnout in Staff Nurses Working in Shebin El-Kom Hospitals, Menoufiya Governernate, Egypt. Life Sci J. 2013; 10(1):3447-3456.

42. El-Demerdash SM, Obied HK. Influence of Empowerment on Nurses' Participation in Decision Making. Nursing Administration Department, Faculty of Nursing, Tanta University, IOSR Journal of Nursing and Health science. 2016; 5(5): 66-72.

43. Valdez G F D, Cayaban A R, \& Mathews, S. Workplace Empowerment, Burnout, and Job Satisfaction among Nursing Faculty Members: Testing Kanter's theory. Nurs Palliative Care Int. 2019; 2(1): 29-35.

44. Taha N. Impact of workplace empowerment on nurses' control over their practice and their job satisfaction at El Manial University Hospital. Cairo University. Doctorate Thesis. 2012: 103-118.

45. Abdelhamied D.H. Relationship between Empowerment and Job Satisfaction among Staff Nurses in Minia University Hospital. Un published Master Thesis, Faculty of Nursing, Minia University, 2017. 250 P.

46. Hassona HMF. Relationship between Structural Empowerment, Work Engagement, and Job Satisfaction among Nursing Staff at Zagazig University Hospitals. Zagazig Nursing Journal. 2013; 9(1): 15-30.

47. Gabra S, Yousef H, \& Abood S A. Relationship between Empowerment and Motivation among Staff Nurses in Minia University Hospital. Un published Master Thesis, Faculty of Nursing, Minia University, 2019.

48. Nasiripour A, Siadati S. A proposed model for nurses' empowerment through characteristics of work place and management strategies, a study in Iranian Hospitals. Aust J Basic\& Appl Sci. 2011; 5(6): 906-911

49. Rawat P. Effect of Psychological Empowerment on Commitment of Employees: An Empirical Study. 2nd International Conference on Humanities, Historical and Social Sciences IPEDR. 2011; 17: 143-147

50. Ibrahim MM, El-Magd M H A, Sayed H Y. Nurse's psychological empowerment and perceived autonomy in university and teaching hospitals at Menofia Governorate/Egypt. J Nurs Educ Pract. 2014; 4(9): 59-68.

51. Saif N I, Saleh A S. Psychological empowerment and job satisfaction in Jordanian hospitals. Int J Human Soc Sci. 2013; 3(16): 250-257.

52. Royan S, Alikhani M, Mohseni M, Alirezaei S, Khosravizadeh O, Moosavi A. Nurses' psychological empowerment in Iran: A systematic review and meta-analysis. Ann Trop Med PH. 2017; 10(6):1558.

53. Tork HM, Alatrash AS, Alharbi AR, Almansour MA, Alolayqi RS .Understanding communication skills learning, behavior and attitude among students in three nursing colleges in Qassim region, Saudi Arabia;2018.

54. Bijani M, Ghodsbin F, Fard SJ, Shirazi F, Sharif F, Tehranineshat B. An evaluation of adherence to ethical codes among nurses and nursing students. J Med ethics Hist Med. 2017;10

55. Radwan AES. Professional competencies among baccalaureate degree nursing graduates: self-report [Master Thesis]. Egypt: Nursing Administration Department, Faculty of Nursing, Alexandria University; 2018.

56. Xie J, Ding S, Wang C, Liu A. An evaluation of nursing students' communication ability during practical clinical training. Nurse educ today.2013; 33(8); 823-827.

57. Shafakhah M, Zarshenas L, Sharif F, Sarvestan RS. Evaluation of Nursing Students' Communication Abilities in Clinical Courses in Hospitals. Glob J Health Sci. 2015; 7(4): 323.

58. Awuah-Peasah D, Sarfo LA, Asamo F. The attitudes of student nurses toward clinical work. Int J Nurs Midwifery. 2013; $5(2): 22-27$.

59. Kajander-Unkuri, S, Suhonen, R, Katajisto, J, Meretoja, R, Saarikoski, M, Salminen, L, Leino-Kilpi, H. Self-assessed level of graduating nursing students' nursing skills. J Nurs Educ Pract. 2014; 4(12): 51-59.

60. Lawal J, Weaver S, Bryan V, Lindo JL. Factors that influence the clinical learning experience of nursing students at a caribbean School of Nursing. J Nurs Educ Pract.2016; 6(4): 3239 .

61. Benner P. From Novice to Expert: Excellence and Power in Clinical Nursing Practice. 4TH Ed. Admission-Wesley Publishing Company. 1984.

62. Joseph Dlama G, Umar A. Perception of Nursing Students and Preceptors about Factors Influencing the Clinical Performance of Nursing Students. IOSR Journal of Nursing and Health Science (IOSR-JNHS). 2015; 4(5):57-69.

63. Gemuhay HM, Kalolo A, Mirisho, R, Chipwaza B, Nyangena E. Factors Affecting Performance in Clinical Practice among Preservice Diploma Nursing Students in Northern Tanzania. Nurs Res Pract. 2019; 1-9.

64. Fikre R. Assessment of Factors Affecting Clinical Practice Competency of Undergraduate Health Science Students in Hawassa University, South, Ethiopia. Ann Clin Lab Res.2016; $4(1)$ 